\title{
Cecal Diverticulitis: An Unusual Endoscopic Finding
}

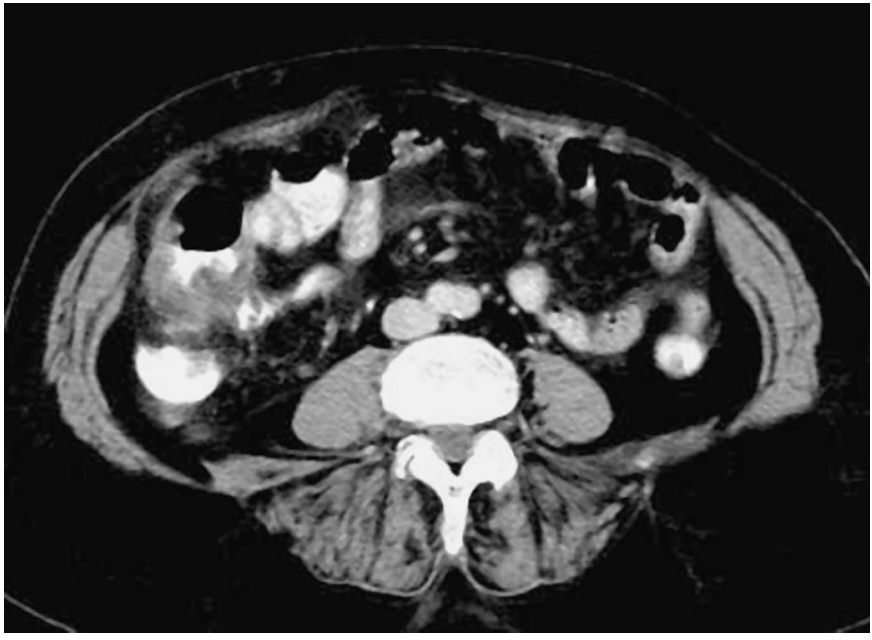

Figure 1 Colonoscopy must be avoided whenever colonic diverticulitis is suspected. However, some patients are diagnosed endoscopically, most of them with left-sided diverticulitis. A 74 year-old woman presented with lower right abdominal pain. Her physical examination did not show any evidence of an abdominal mass or any peritoneal signs. Complementary studies showed a neutrophil count of $10950 / \mathrm{ml}$ and cecal wall thickening, with distortion of the surrounding fatty tissue on abdominal computed tomography, suggesting a colonic tumor.
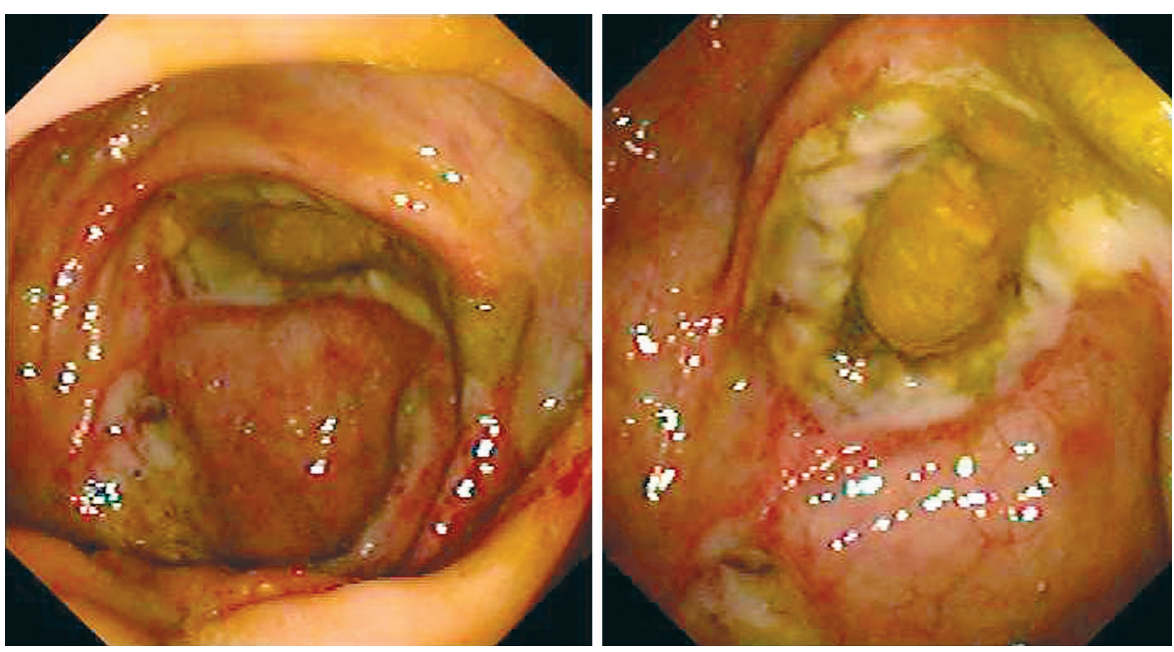

Figure 2 Colonoscopy revealed fecal impaction inside a diverticular orifice close to the appendix, with severe mucosal inflammation surrounding it. There was no evidence of neoplasm. Diverticulectomy and appendectomy were carried out, with no postoperative complications: clinical practice, right-sided colonic diverticulitis is a rare finding, and a colonoscopic diagnosis is exceptional.
F. J. Fernández-Pérez, C. De Sola, N. Fernández-Moreno, R. Rivera-Irigoin, E. Ubiña-Aznar, G. García-Fernández, J. M. Navarro-Jarabo, P. Moreno-Mejías, A. Ibañez-Pinto, A. Sanchez-Cantos Dept. of Gastroenterology, Costa del Sol Hospital, Marbella, Spain

\section{Corresponding Author}

\section{F. J. Fernández-Pérez, M.D.}

Dept. of Gastroenterology

Costa del Sol Hospital

Ctra. Nacional 340, Km 187

Marbella 29600, Malaga

Spain

Fax: $\quad+34-952-823219$

E-mail: ffernandezp@meditex.es 